Claves. Revista de Historia, Vol. $3, \mathrm{~N}^{\circ} 4$

Montevideo, Enero-Junio 2017

(pp. 77-104) ISSN 2393-6584

\title{
Los límites de la confianza. Prejuicio y persecución contra servidoras domésticas en Jalisco a finales del siglo XIX
}

\section{The limits of trust. Prejudice and persecution against domestic servants in Jalisco at the end of the 19th century}

Miguel Ángel Isais Contreras Universidad de Guadalajara, México.

Recibido: $16 / 03 / 2017$

Aceptado: 06/06/2017

Resumen: El presente trabajo aborda las representaciones en la opinión pública de Guadalajara durante el siglo XIX acerca de las mujeres que trabajaban en el servicio doméstico. El artículo estudia las opiniones en torno a la ociosidad y las conductas parasitarias que endilgaban a los sectores populares los varones -médicos y jurisprudentes principalmente- que enarbolando el liberalismo mexicano y promoviendo los valores de la ciudadanía, procuraban la desaparición o al menos el control o supervisión de dichas conductas. Lejos de haber sido una política dirigida exclusivamente a los hombres, también tuvo como foco de atención a las mujeres, al tratar de identificar los espacios donde ellas podían "degenerar", convirtiéndose en amenaza a la seguridad de la sociedad y de las familias de la ciudad.

Palabras clave: ociosidad, justicia, servicio doméstico, mujeres.

Abstract: The present work deals with public opinion representations of women working in domestic service, in 19th century Guadalajara. The article studies how males (physicians and layers, mainly), who permanently raised Mexican liberalism and promoted citizenship values, attributed idleness and parasitic behavior to popular sectors, trying to ensure the disappearance, or at least the supervision, of this conducts. Far from being a policy exclusively thought for men, it also paid attention to women, trying to identify those areas where they could "degenerate", becoming a threat to city families and society.

Keywords: Idleness, justice, domestic service, women. 


\section{Introducción}

El presente artículo es un acercamiento a los discursos y a la vida cotidiana de un sector de mujeres que poco se conocen dentro de la historiografía mexicana y, en particular, jalisciense. Es el caso de aquéllas que conformaron parte de los sectores menos privilegiados de la sociedad, cuya vida pública y laboral comúnmente se redujo al servicio doméstico, siendo su presencia progresivamente una molestia para las élites que las contrataban. No obstante, aunque se mantuvo latente una red paternalista entre amos y sirvientes, cualquier descuido o indicio que diera pie a la desconfianza, la relación se rompía. Cuando la reprimenda no parecía ser suficiente, las élites porfirianas cada vez contaron con mayores recursos legales para protegerse de sus trabajadores deshonestos. De esta manera, al final del presente estudio se presentan algunas rupturas entre amos y sirvientes, sobre todo por episodios de conflicto y exaltación, que las fuentes judiciales nos permiten conocer. Tales documentos, pese a provenir de una institución de control social, permiten rescatar el sentir y la opinión no solo de las autoridades y denunciantes, sino también de los acusados, una voz poco atendida en la historiografía mexicana.

En la medida que la perspectiva de género y la historia del trabajo confluyeron en una dinámica que asentó las bases de una muy peculiar historiografía, muchos de los primeros estudios hicieron esfuerzos por tratar de decodificar el desenvolvimiento de las mujeres dentro de la era industrial europea iniciada a fines del siglo XVIII. ${ }^{1}$ Sin embargo, tras indagar sobre algunas obras importantes de esa copiosa corriente historiográfica, uno se puede percatar que la mayoría de las veces éstas apuntalan la elevada participación femenina en el mundo industrial, lo cual es innegable, pero desestiman las iniciativas reformistas que forzaron a las mujeres a ingresar, muchas veces contra su voluntad, al nuevo orden socio-laboral.

\footnotetext{
${ }^{1}$ Como ejemplo, se puede hacer mención del libro editado por Mary Nash en 1984, en el que participan investigadores como Joan W. Scott, Lynn Douglas y Charles Rosengberg, entre otros. Obra colectiva que en su primera parte rememora el importante activismo de la mujer en la vida pública y laboral. Presencia y protagonismo. Aspectos de la historia de las mujeres, Barcelona, Ediciones del Serbal, 1984.
} 
Esta visión surge debido a que, al menos para el contexto latinoamericano, se desdobló el discurso sobre la incursión de las mujeres en la vida laboral durante el siglo XIX. Unos rechazaban rotundamente que las mujeres ingresaran en las fábricas, pues desatendían sus "exclusivas" labores domésticas poniendo en riesgo el núcleo familiar; y otros, aplaudían la existencia de mujeres obreras pues se creía que ese era un medio para que evitaran caer en la ociosidad y degeneración que trascendían a toda la sociedad, ${ }^{2}$ ya que por definición durante esta época, la degeneración de las mujeres se hacía patente en la prostitución. El objetivo de este trabajo refiere a ese debate y tiene como objetivos presentar y analizar algunos discursos que se fundamentaron en el derecho y en la medicina, puesto que la mujer adquirió un particular modo de ser, a causa de estas disciplinas que reforzaban sus roles dentro de las leyes y la vida social.

La historiografía que ha girado alrededor de los estudios sobre el servicio doméstico ha tenido enfoques desde perspectivas teóricas y metodológicas diversas, de acuerdo incluso con las épocas que los distinguen. En sus inicios lo abordó desde la historia social, atendiendo a las mujeres en el mundo laboral y su incursión en la vida pública en un marco de desarrollo de las naciones. ${ }^{3}$ Asimismo, asociando al servicio doméstico con la prostitución, una visión que ha podido demostrar que ante las escasas posibilidades de que las mujeres ejercieran un trabajo, el servicio doméstico y en el peor de los casos la prostitución, fueron casi sus únicas opciones. Lo característico de esta visión es que desde ambas actividades las mujeres debieron quedar sujetas a variados reglamentos de control. 4

\footnotetext{
2 PORTER, Susie R. Working women in Mexico City. Public discourses and material conditions, 1879-1931, Tucson, The University of Arizona Press, 2003; RAMOS ESCANDÓN, Carmen. Industrialización, género y trabajo femenino en el sector textil mexicano: el obraje, la fábrica y la compañía industrial, México, CIESAS, 2005; PÉREZ TOLEDO, Sonia. "Trabajadores urbanos, empleo y control en la Ciudad de México", en Clara LIDA y Sonia PÉREZ TOLEDO (comps.). Trabajo, ocio y coacción. Trabajadores urbanos en México y Guatemala en el siglo XIX, México, Universidad Autónoma Metropolitana-Iztapalapa / Miguel Ángel Porrúa, 2001, pp. 157-198.

3 Para el caso de México no puede dejar de mencionarse el trabajo de ARROM, Silvia M. Las mujeres de la ciudad de México, 1790-1857, México, Siglo XXI, 1988.

4 Se pueden destacar los siguientes trabajos: NÚÑEZ BECERRA, Fernanda, Las prostitución y su represión en la ciudad de México (siglo XIX). Prácticas y representaciones. México, Gedisa, 2002; BLISS, Katherine Elaine. Compromised positions. Prostitution, public health, and gender politics in revolutionary Mexico City, University Park, The Pennsylvania State
} 
Una línea de investigación que aporta a la consideración del tema, es la renovación que han tenido los estudios sobre la esclavitud en la América española, pues puede asegurarse que de ésta se desprenden las formas de relación que giran alrededor del servicio doméstico, como el paternalismo.5 En la medida en que las diversas metodologías de las ciencias sociales han sido incorporadas al estudio de la historia, los estudios sobre el trabajo y el servicio doméstico han presentado notables giros discursivos, dando paso de un estructuralismo a análisis de carácter más interdisciplinarios, que van desde la historia cultural hasta la historia de género y de la vida cotidiana. ${ }^{6}$

La presente investigación es un propuesta que invita a acudir a las fuentes judiciales, no sólo para retomar el tema del servicio doméstico dentro de la historiografía (el cual espero brinde posibilidades para repensarlo), sino en general de temas y actores que no están implícitos por fuerza en la justicia. Las fuentes judiciales del ramo criminal no sólo nos permiten estudiar los espacios del delito y de la transgresión, sino que también nos sirven para conocer a otros actores que a veces de manera tangencial fueron registrados, tales como mujeres, niños, artesanos, enfermos, indigentes, propietarios, empleados y una larga lista de oficios y ocupaciones que comprendieron el mundo del empleo y subempleo en México. El ensayo sugiere la hipótesis de que por más que se dignificara desde la opinión pública y la literatura la función de los servidores

University Press, 2001; y recientemente el libro coordinado por Elisa SPECKMAN y BAILÓN, Fabiola. Vicio, prostitución y delito. Mujeres transgresoras en los siglos XIX y XX, México, UNAM-Instituto de Investigaciones Históricas, 2016.

5 No se puede ignorar aquí el trabajo de GENOVESE, Eugene. Roll Jordan roll: The world the slaves made, New York, Pantheon, 1974; asimismo se pueden destacar tres trabajos que retoman el tema de la esclavitud desde sus implicaciones políticas, de género, económicas, étnicas e identitarias: BORUCKI, Alex, From shipmates to soldiers. Emerging Black identities in the Río de la Plata, Albuquerque, University of New Mexico Press, 2015; MCKINLEY, Michelle A. Fractional freedoms. Slavery, intimacy, and legal mobilization in colonial Lima, 1600-1700, New York, Cambridge University Press, 2016; LIPSETT-RIVERA, Sonya, Gender and the negotiation of daily life in Mexico, 1750-1856, Lincoln and London, University of Nebraska Press, 2012.

${ }^{6}$ SARASÚA, Carmen. Criados, nodrizas y amos. El servicio doméstico en la formación del mercado de trabajo madrileño, 1758-1868, Madrid, Siglo XXI de España Editores, 1994; BAILÓN, Fabiola, "Trabajadoras domésticas y sexuales en la ciudad de Oaxaca durante el Porfiriato: sobrevivencia, control y vida cotidiana", Tesis de doctorado en Historia, El Colegio de México, 2012; y muy recientemente se destaca el libro de Cecilia L. ALLEMANDI, quien buscó concentrar el tema del servicio doméstico desde afuera de la esfera doméstica, a través de la reglamentación, desde su importancia económica, de las prácticas culturales, en síntesis, de su representación. Véase Sirvientes, criados y nodrizas. Una historia del servicio doméstico en la ciudad de Buenos Aires (fines del siglo XIX y principios del XX), Buenos Aires, Universidad de San Andrés / Teseo, 2017. 
domésticos desde mediados del siglo XIX, conforme culminaba el siglo el reglamentarismo que se hizo presente durante el porfiriato en casi todos los espacios públicos, implicó el control social aplicado a los sirvientes, quienes debieron ser registrados cual si fueran delincuentes dado que su actividad guardaba estrecha relación con el delito. Las familias de Guadalajara parecían que ya no depositaban la misma confianza sobre sus empleados, y la justicia creó una circunstancia agravante para que aquellas las pudieran utilizar a su favor: el abuso de confianza. Al final de este estudio se presentan algunos casos tomados de expedientes judiciales que testimonian un proceso generalizado de ruptura de un elemento central en las relaciones laborales entre patrones y sirvientes: la confianza.

\section{Tras una tipología oculta del bello sexo}

Durante el siglo XIX en México se aplicó una recurrente persecución contra la vagancia y, en concreto, contra los hombres que la llegaban a manifestar más por suspicacias del vulgo que por la aparente voluntad que pudieron llegar a tener hacia semejante conducta. En términos jurídicos, la vagancia en el siglo XIX se constituyó por un conjunto de tipologías sociales que tenían por común denominador la deshonestidad, el desempleo y la vida desarraigada de toda vecindad. Por lo tanto, el Estado implementó una serie de sanciones que buscaban en teoría revertir el comportamiento de muchos hombres que invariablemente cayeron en la vagancia, destinando para unos el servicio a las armas y, para otros los arrestos, los destierros y las obras públicas.7

\footnotetext{
7 Existe una amplia bibliografía sobre el estudio de la vagancia en México, investigaciones que se enfocan primordialmente al caso de la ciudad de México y parten del final del siglo XVIII a la mitad del siglo XIX: ARROM, Silvia M. "Vagos y mendigos en la legislación mexicana, 17451845", en BERNAL (coord.), Memoria del IV Congreso de Historia del Derecho Mexicano, t. I, México, UNAM-Instituto de Investigaciones Jurídicas, 1988, pp. 71-88; ARROM, Silvia M. "Documentos para el estudio del Tribunal de Vagos, 1828-1848. Respuesta a una problemática sin solución", en BERNAL (dir.), Anuario Mexicano de Historia del Derecho, México, UNAMInstituto de Investigaciones Jurídicas, 1989, pp. 215-235; PÉREZ TOLEDO, Sonia, Los hijos del trabajo. Los artesanos de la ciudad de México, 1780-1853, México, Universidad Autónoma Metropolitana-Iztapalapa/El Colegio de México, 1996; TEILTELBAUM, Vanesa E. "La corrección de la vagancia. Trabajo, honor y solidaridades en la ciudad de México, 1845-1853" en LIDA y PÉREZ TOLEDO (comps.), Trabajo, ocio y coacción. Trabajadores urbanos en México y Guatemala en el siglo XIX, México, Universidad Autónoma Metropolitana-Iztapalapa/Miguel Ángel Porrúa, 2001, pp. 115-156. Y para el caso de Jalisco: ISAIS CONTRERAS, Miguel Ángel, Vagos y perniciosos en Jalisco (1867-1887). Una aproximación al estudio de la marginación y reintegración forzada, México, Tesis de Maestría en Historia, Facultad de Filosofía y letrasUNAM, 2005.
} 
Ante estos hechos, bien vale la pregunta de si este aparato de control se aplicó indistintamente contra hombres y mujeres; o bien si se penalizó conforme a una categoría de género. Durante el mes de julio de 1856 el gobierno del Estado de Jalisco intentó acotar aun más la legislación en torno a la vagancia, a través de una circular que ponía fin a la persecución hacia las mujeres vagas, debido a que ellas, a diferenta de los hombres vagos, no podían corregir su vagancia ejerciendo alguna ocupación u oficio, dado que éstos eran comúnmente aplicados a los hombres. ${ }^{8}$

Esto último lleva a pensar que la mujer quedaba excluida de todo aquel proceso reformista, pues como bien lo apuntó esa circular, el Estado implícitamente dejaba en claro el papel de la mujer dentro de la sociedad, ya que si las leyes contra la vagancia tenían la función de dotar "ocupación y dedicación a algún oficio" a los que carecieran de ellos, esto mismo no podía hacerse con las mujeres, cuyas labores debían granjearse en otras áreas. Ellas, por tanto, parecía que quedaban fuera de la mirada policial y, a partir de esa fecha, no involucradas íntimamente con los delitos de vagancia.

Pero la mujer no estuvo del todo excluida de las miradas reformistas y utilitarias vigentes durante el siglo XIX, sobre todo la mujer pobre, que si bien no podía ser acusada de vagancia continuaba siéndolo de otros delitos, tanto leves como graves, que la emparentaba criminalmente con los que cometían los hombres. Las mujeres, al igual que los hombres, debieron cumplir con su instrucción y dedicación a ciertas labores en beneficio de la familia y de la sociedad, pues a la par de haber fungido como el pilar moral de aquélla, a la vez tenían que hacerle frente a su subsistencia con afanes honrosos en la esfera pública. Así, y de acuerdo con Silvia Arrom, era totalmente aceptado que la mujer pobre participara en el medio laboral, existiendo para ella solo dos caminos: el de la maternidad y el del trabajo. ${ }^{9}$ Sin embargo, en distintos momentos se enarboló un rotundo rechazo a que las mujeres se involucraran en el medio fabril, debido al temor de mezclar a hombres y mujeres dentro de un mismo espacio, desatándose una confusión de los roles de género y una

8 Colección de los Decretos, $1^{\text {a }}$ colección, t. XIV, Tip. de Gob. a cargo de J. Guadalupe Montenegro, 1884, p. 92.

9 ARROM, Las mujeres de la ciudad de México... op. cit, pp. 41-46. 
desnaturalización de la imagen femenina. Esto se suscitó pese a que, en opinión de grupos reformistas, la actividad industrial de las mujeres coadyuvaría a la regeneración social, disminuyendo, por ejemplo, la prostitución.10

Sin embargo, existió un temor todavía mayor surgido a partir de la incursión de las mujeres en la vida fabril, el que, como sucedió en la Londres victoriana, respondía a la creencia de un riesgo de degradación moral de las mujeres y que, incluso, podría extenderse sobre toda la sociedad. La mujer pobre, se entendía entonces, era claro que debía trabajar, pero en áreas afines a su condición natural. ${ }^{11}$

En Argentina durante la segunda mitad del siglo XIX, al igual que en México, se promovió un reformismo social que aparejó la búsqueda de un nuevo "sujeto moral", el cual debía involucrarse de manera responsable en la vida laboral para beneficio de la sociedad, garantizándose, se creía, la salud y la moral del pueblo. Este proceso se advierte que sólo involucró a los hombres, ${ }^{12} \mathrm{y}$ para el caso de México tal vez se ha llegado a pensar lo mismo. El trabajo, actividad que se reconocía sólo de manera pública y fuera del hogar, era inapropiado para las mujeres porque éstas, al enrolarse en la vida laboral, ejercían una "doble carga" de trabajo, acción por la que al final serían reprochadas debido al riesgo y vulnerabilidad en que dejaban a sus hijos sin prodigarles las atenciones necesarias. Además, era inaceptable que las mujeres embarazadas trabajasen, ya que con semejantes faenas se estaba en riesgo de sobrellevar abortos o insuficiencias en los recién nacidos; en fin, se caía en el efecto fatídico de la degeneración de la raza. ${ }^{13}$

Las mujeres de los sectores populares fueron comúnmente sujetas al trabajo forzado, que se producía tanto en el círculo doméstico, a iniciativa de los

\footnotetext{
10 PORTER, op.cit., pp. 53-59.

${ }^{11}$ ALEXANDER, Sally, "La mujer trabajadora en el Londres del siglo XIX: un estudio de los años 1820-50", en NASH (ed.). op. cit., pp. 142-144.

12 NARI, Marcela M. A., "Conflicto social, maternidad y degeneración de la raza", en Lea FLETCHER (comp.), Mujeres y cultura en la Argentina del siglo XIX, Buenos Aires, Feminaria Editora, 1994, p. 212.

13 NARI, op. cit., p. 211.
} 
padres, como por parte de las autoridades. ${ }^{14}$ En México se establecieron casas correccionales o de recogimiento desde mediados del siglo XVI y, en Guadalajara, en 1776 se instituye la primera Casa de Recogidas.15 En esta se buscó disciplinar a las internas en las labores del hilado y el tejido o en el fortalecimiento de sus prácticas religiosas. A mediados del siglo XIX fue reestructurada dicha casa con la finalidad de no mezclar a las internas "inocentes, o no del todo corrompidas", con las que merecían toda una corrección, posiblemente mujeres catalogadas como desobedientes o de costumbres relajadas. ${ }^{16}$

Vemos entonces que las casas de corrección y los aprendizajes se aplicaron indistintamente para hombres y mujeres, siempre bajo un principio de separación por sexo para evitar que interactuaran bajo un mismo espacio. A las élites científicas, católicas y de beneficencia no solo les importaba que las mujeres corrigieran su conducta con labores meramente domésticas, sino que procuraron inculcarles un apego más útil al trabajo, como dedicarse a las manufacturas; es decir, por igual buscaban despejar dentro de sus costumbres toda ociosidad y holgazanería.

En palabras de la poetisa jalisciense Refugio Barragán de Toscano, el problema del porvenir femenino no radicaba tanto en la mujer pobre, sino en la "aristócrata", pues la primera había permanecido más habituada "a ganarse las más de las veces el sustento por sí misma” desempeñando trabajos más pesados; en cambio, la mujer rica, muchas veces educada con ciertas

\footnotetext{
14 Por ejemplo, en la Ámsterdam del siglo XVII se contaba con dos clases de casas de corrección o "recuperación": una para la población más desheredada (werkhuis), y otra que atendía a las demandas de los padres o tutores que acudían ante las autoridades para solicitar la corrección de sus hijas mediante el pago de una pensión (spinhuis). Ambos establecimientos se instituyeron con la intensión de dotar de oficios nobles y honestos a las jóvenes de las familias holandesas, todo con el claro objetivo de evitar que llegaran a la holgazanería y al vicio de la prostitución; ya que para la opinión pública de Ámsterdam, toda mujer que no se condujera como era debido, se le consideraba "una puta". POL, Lotte van de, La puta y el ciudadano. La prostitución en Ámsterdam en los siglos XVII y XVIII, trad. de Cathy Ginard Féron, Madrid, Siglo XXI, 2005, pp. 107-111.

15 Véanse al respecto, por ejemplo: MURIEL, Josefina. Los recogimientos de mujeres Respuesta a una problemática social novohispana, México, UNAM, 1974; RODRÍGUEZ RAYGOZA, Elizabeth, "La casa de recogida, una institución para proteger, corregir y castigar a las mujeres en Guadalajara durante los siglos XVIII-XIX”, en Revista del Seminario de Historia Mexicana. Conductas, imaginarios y roles femeninos. siglos XVIII a XX, núm. 2, verano de 2009.

16 "Reglamento para el gobierno interior de la casa de recogidas" (1829), en Colección de los Decretos, t. III, $1^{\text {a }}$ Colección, pp. 339-343.
} 
aspiraciones y delicadezas, se tornaba pretenciosa y vanidosa. Una vez que ésta sentía repugnancia al trabajo, "el tedio la consume, un malestar continuo la domina, y su cuerpo, falto de ese vigor que sólo proporciona el trabajo, se va consumiendo poco a poco en la inacción”. ${ }^{17}$

Sin embargo, a diferencia de lo que estimó Barragán, se ha podido observar que las exigencias de la virtud femenina se descargaron mayormente hacia la mujer pobre, la cual, de no poner cuidado en su educación y laboriosidad, quedaba más expuesta a desempeñar una vida parasitaria bajo el ejercicio de la prostitución, considerado un signo degenerativo pues como ha sugerido Rafael Sagredo, la prostitución representó "una forma de vida incompatible con el trabajo y la vida productiva". ${ }^{18}$ Esta clase de discursos parecían destinados a detectar la vida parasitaria de las mujeres, una condición tipológica y social de las mujeres vagas.

Sin embargo, existieron otras actividades que de igual manera descalificaron el papel desarrollado por las mujeres en su vida pública, caso de las sirvientas domésticas o criadas quienes, al ser refractarias a la educación que pudieran prodigar las principales familias encargadas de su custodia más que de la demanda y remuneración justa por sus servicios, quedaban a un paso de la liviandad y el crimen. ${ }^{19}$

\section{El discurso contra el servicio doméstico}

A finales del siglo XIX dos catedráticos de Bruselas, Emile Vandervelde y Jean Massart (el primero dedicado al Derecho y al Estado y el segundo a la Botánica y a la Medicina), conjugaron sus intereses y conocimientos para desarrollar una teoría e interpretación de la sociedad, que adquirió seguidores aun fuera de Europa. Surge así la idea corriente del parasitismo social, la cual

\footnotetext{
17 BARRAGÁN DE TOSCANO, Refugio. "Mejoramiento de la mujer. Discurso sobre su educación actual, pronunciado en la Sociedad 'Las Clases Productoras' de Guadalajara”, El Hijo del Trabajo, n. 322, México, D. F., 15 de octubre de 1882, p.1.

18 SAGREDO BAEZA, Rafael, "La prostitución en el Porfiriato: El caso de la Chiquita", en O'PHELAN, MUÑOZ, JOFFRÉ Y SÁNCHEZ (coords.), Familia y vida cotidiana en América Latina, siglos XVIII-XIX, Lima, Pontificia Universidad Católica del Perú/Instituto Francés de Estudios Andinos, 2003, pp. 379-408.

19 AGUIRRE, Carlos. "Mujeres delincuentes, prácticas penales y servidumbre doméstica en Lima (1862-1930)”, en O'PHELAN, MUÑOZ, JOFFRÉ Y SÁNCHEZ (coords.), op. cit., pp. 203-226.
} 
estructuraron de manera gradual entre predatarios, sexuales, políticos y propietarios, todo, claro está, mediante una simbiosis orgánica y social. En el fondo, sus estimaciones demarcaron fenómenos cargados desde antes por una fuerte apreciación moral y política. Dichos autores afirmaron que la prostitución, o más exactamente sus agentes (proxenetas, padres, rufianes y alcahuetes), constituían elementos que afectaban al cuerpo social. ${ }^{20}$ En otro momento, analizaron la figura de las clientelas o los sirvientes domésticos, a los que igualmente englobaron como parásitos por vivir siempre a la sombra de sus amos, de quienes adquirían confianza y muchos otros beneficios a tal grado, que les permitía llevar una vida cómoda y a veces hasta honrosa. ${ }^{21}$

Las ideas de Vandervelde y Massart fueron seguidas en México por el médico Luis Lara y Pardo, quien en un estudio sobre higiene social de la prostitución, afirmó que ésta debía reconocerse como un síntoma de degeneración social. La mujer, dijo, cuando hereda la "inferioridad psicológica, moral y social", la mayoría de las veces termina en la prostitución, agregando que las mujeres que ejercían esa actividad constituían en "la especie más rudimentaria, la más degenerada de parásito social. ${ }^{22}$

El trabajo de Lara y Pardo desplegó algunas críticas al reglamentarismo que existía en México sobre la prostitución, que en vez de erradicarla, mantuvo una constante tolerancia. A su entender había que revelar cómo se estructuraba la prostitución al menos en la ciudad de México, para atacar después el problema desde sus orígenes. Entre sus primeros datos, para él reveladores, estaba la significativa cantidad de mujeres domésticas y otras "sin oficio", inscritas en los registros de la Inspección de Sanidad, lo cual arrojaba indicios sobre el germen de la prostitución y degradación de las mujeres.

Incluso identificó uno de los lugares donde más se arrojaba a la prostitución a las mujeres, precisamente la ciudad de Guadalajara, "la patria obligada de las prostitutas". Para Lara y Pardo parecía tan cierto que las mujeres

20 VANDERVELDE, Emilio y Juan MASSART, Los parásitos de la sociedad. Estudio comparativo sobre los parásitos de la sociedad y los de la naturaleza, trad. del francés por J. Comaposada, Barcelona, F. Granada y Ca. Editores, 1906 (1893), p. 33.

${ }_{21}^{1}$ Íbid., pp. 85-86.

${ }^{22}$ LARA Y PARDO, Luis. La prostitución en México, México, Librería de la Vda. De Bouret, 1908, pp. 90, 109. 
tapatías eran "hembras hermosas, fáciles y ardientes", como el hecho de que también representaban el gran número de prostitutas "de cartel” que existían en la ciudad de México. En parte compartía esta opinión, pues consideraba que las mujeres jaliscienses fueron herederas de un cruzamiento de razas que se dio en condiciones "más favorables", es decir, con un predominio de la tez blanca de la raza conquistadora, produciéndose un mestizaje de aspecto "bastante agradable":

\begin{abstract}
"Este mestizaje penetró profundamente hasta las capas últimas del pueblo, de manera que no es raro encontrar entre las mujeres de nivel social más bajo, caras expresivas, hermosos ojos rasgados, estaturas elevadas y formas gráciles.”23
\end{abstract}

Estos distintivos raciales, según Lara, llevaban a muchas buscadoras de mujeres y proxenetas a visitar la "Perla de Occidente" para llenar de mayor atractivo sus lupanares; el enganchamiento muchas veces tenía lugar captando mujeres del servicio doméstico. ${ }^{24}$ En otro momento puso el acento en el proceso migratorio de hombres y mujeres que abandonaban sus pueblos para tratar de ingresar al mercado laboral de las grandes ciudades. La mayoría de las mujeres que arribaban a Ciudad de México luego de abandonar sus hogares en otros estados del país, no tenían más oportunidad de trabajo que el servicio doméstico.

Tales condiciones le permitieron a Lara encontrar en el servicio doméstico el germen de la prostitución y la degeneración de las mujeres consideradas en su mayoría: "perezosas, viciosas, hasta ladronas y

\footnotetext{
23 Íbid., p. 54.

24 Esta caracterización de las mujeres tapatías ya desde antes la había detectado y/o divulgado el periodista e inspector de policía, Carlos Roumagnac, en su galería de criminales mediante entrevistas que realizó a hombres y mujeres en la Penitenciaría de Belén, en Ciudad de México a inicios del siglo XX. De ahí se difunde la figura de María Villa (a) "La Chiquita" (personaje de la nota roja porfiriana que ya se ha trabajado ampliamente: véase SAGREDO BAEZA, Rafael. María Villa (a) La Chiquita, no. 40o2. Un parásito social del Porfiriato, México, Cal y arena, 1996) o la de Emilia M, mujer originaria de Guadalajara y detenida por homicidio. Según inquisitivas que le hizo Roumagnac, Emilia desde muy pequeña quedó huérfana y después bajo el cuidado de unos tíos que la maltrataban, quienes finalmente la trasladaron a Ciudad de México, donde comenzó en la servidumbre y con el vicio del alcohol. Entre el repertorio también aparece la figura de Ángela R., mujer también originaria de Guadalajara y que siendo muy joven sus padres la llevaron a la ciudad de México. Señaló que, aunque tuvo la posibilidad de estudiar, prefirió trabajar como criada, condición que la conectó con el mundo de la prostitución hasta el grado de llegar a ejercer el lenocinio y el safismo. ROUMAGNAC, Carlos. Los criminales en México. Ensayo de psicología criminal, México, Tipografía "El Fenix”, 1904.
} 
asquerosamente enfermas.” Éste es el punto en el que encuentra un paralelismo con el estudio de Vandervelde y Massart: "aquellos que viven a expensas de otro, sin producir absolutamente nada [...], se acercan más a la condición del simple parásito". ${ }^{25}$ Con estos argumentos puede verse que buena parte del trabajo de Lara y Pardo se concentró en demostrar, mediante casos aislados y prejuicios muy remarcados, que una de las fuentes de la propagación de la prostitución y de las enfermedades venéreas recaía en la perjudicial actividad de sirvientas y niñeras.

Asimismo, advirtió que la pobreza no era la causa de ese degenerado estado de las mujeres que se inclinaban al vicio y a la prostitución y, en su lugar, invocó la fuerte influencia de una conducta que por entonces los teóricos sociales y criminólogos defendían: la imitación. En palabras del doctor Lara, era vital "la influencia de la imitación como agente propagador de todos los vicios, de todas las depravaciones, de todas las formas de degeneración social". ${ }^{26}$ Un proceso que se hacía patente en las jóvenes que recién llegadas a la ciudad adquirían enseguida conductas de mujeres ya corrompidas. Lara estaba lejos de poseer de un pensamiento sui géneris sobre el fenómeno de la prostitución; al contrario, si presentó semejante estudio fue porque en México, a diferencia de otros países, se carecía de uno semejante. ${ }^{27}$

En 1854 salió a la luz en México la obra colectiva Los mexicanos pintados por si mismos, obra hecha por y para las clases ilustradas del país que, bajo un incipiente espíritu nacionalista cargado de nociones racistas y prejuiciosas, intentó recrear la amplia tipología social que predominaba en México, desde los oficios y profesionistas mejor reconocidos hasta los trabajadores más humildes y perceptibles dentro de la vida social. En dicha obra aparece la figura de los

\footnotetext{
25 LARA Y PARDO, op. cit, p. 112.

${ }^{26}$ La imitación fue una corriente de análisis social desarrollada por el sociólogo y criminólogo francés Gabriel Tarde, quien a finales del siglo XIX difundió bajo su obra Les lois de l'imitation; trabajo que tuvo pocos seguidores (E. Durkheim, G. Le Bon, E. Vandervelde) por no ser una hipótesis suficientemente convincente, pues en esencia declaraba que la imitación "era un hecho social básico y existían leyes que describían su naturaleza y su efecto. El cambio social es posible porque la gente imita lo más nuevo y lo sorprendente". KLINEBERG, Otto, Psicología social, trad. de Victorino Pérez, México, Fondo de Cultura Económica, 1992, p. 414.

27 Por ejemplo, a finales del siglo XIX el médico español Prudencio Sereñana ya había establecido una fuerte relación entre el servicio doméstico y la prostitución, salvo que para él la causa sí radicaba en la pobreza, el desempleo y los bajos salarios. SARASÚA, op.cit., pp. 251252.
} 
sirvientes domésticos descritas por las plumas de algunos de sus colaboradores, como Niceto de Zamacois y Pantaleón Tovar. El primero refirió que era casi injusto seguir calificando a los sirvientes como ladrones e indignos de toda confianza. Al contrario (y bajo el mismo propósito de la obra, que se esforzaba en ennoblecer los oficios), buscó con ejemplos muy sutiles y recreaciones ficticias reivindicar el origen y la labor de los criados, quienes por principio y casi por definición provenían de las comunidades indígenas, pasando miserias y tempestades.

Del mismo parecer fue Pantaleón Tovar, aunque no olvidó mencionar algunas características, a su entender muy divulgadas, referidas a los sirvientes, en especial, las domésticas. Señaló que era común que las criadas, al no desprenderse de sus relaciones personales con amantes y compadres, era fácil que ventilaran la vida cotidiana de sus amos, así como el valor de sus pertenencias. Estas mujeres, a veces engañadas por sus allegados y otras en complicidad con ellos, daban pie a la comisión de grandes robos:

“...ella es la primera, que luego que se han escapado los ladrones, da voces y grita y da sus señas, y se queja de todos los males que le han hecho, y sus amos la compadecen y la conservan a su lado; pero ella que ya hizo su negocio, se despide llorando por la desgracia que aflige a los que les come el pan, se marcha con la música a otra parte, gasta en algunos días el producto de su compadrazgo, y vuelve a las andadas con las mismas precauciones, y casi siempre con el mismo éxito. Cuidado con estas, carísimos lectores! Porque si no, el día menos pensado os quedais sin calzoncillos..."28

Por influjo del higienismo de finales del siglo XIX, la imagen de los sirvientes fue altamente vituperada, ya que al provenir de los estratos más bajos (y por consiguiente más proclives a padecer enfermedades), eran considerados agentes de contagio principalmente de la sífilis o la tuberculosis. La imagen de sirvientes y criados muy pocas veces pudo ser peor, pues además de portar enfermedades por igual se les atribuía ser sujetos ajenos a toda honradez y entidad jurídica (vale recordar que para este tiempo también eran excluidos de voto), y sí muy inclinados al vicio y al delito.

${ }^{28}$ Los mexicanos pintados por si mismos. México, Editora Nacional, 1959, p. 107. 
En 1901 el jurisconsulto Julio Guerrero refrendó esta clase de prejuicios socio-raciales y atavismos propios del pensamiento penal positivista de finales del siglo XIX, al considerar que entre las criadas se percibía una generalizada degeneración tanto moral como racial, señalando como evidencias de esa condición los prognatismos y otras deformidades. A su entender, las sirvientas eran presuntuosas, ostentosas y de "moral relajada", razón por la cual no se podía confiar en ellas, dado que incluso llegaban a difamar "a las personas que sirven”. Una condición que, en su definición, las colocaba al borde del crimen impulsándolas a cometer abortos, infanticidios y robos, esto último para "obsequiar a sus amantes". 29

Así, tanto para Pantaleón Tovar como para el mismo Guerrero, parecía que no debía pasarse por alto, sobre todo por el significativo valor que tenían en el mercado (como en tendajones y montepíos ${ }^{30}$ ), objetos tan personales como las prendas: sombreros, frazadas, enaguas...o los "calzoncillos", como tal vez irónicamente sostenía Tovar. Por más pintoresco que haya sido Los mexicanos pintados por sí mismos, el sentir hacia los servidores domésticos no los mostró con las mejores de sus cualidades; al contrario, trascendía una ambigua imagen que oscilaba entre la desconfianza y la deshonestidad. Conforme el reglamentarismo se fue extendiendo con la política porfiriana sobre algunas ciudades importantes del país, los sirvientes, poco después, también fueron objeto del control social a iniciativa de las mismas familias que utilizaban sus servicios, que al parecer ya no confiaban plenamente en ellos.

Previo a ello, cuando el 1871 fue emitido el primer Código Penal para el Distrito Federal y territorios de la Federación (mismo que a la postre se adoptó en casi todo el país), Antonio Martínez de Castro, autor de la exposición de

29 GUERRERO, Julio, La génesis del crimen en México. Estudio de psiquiatría social, México, Consejo Nacional para la Cultura y las Artes, 1996 (1901), pp. 139-140.

3o De acuerdo con Marie Eileen Francois, las mujeres, sobre todo las pobres y viudas, eran las que más acudían a los montes de piedad como un medio para lograr su subsistencia, dado que en ellos podían empeñar prendas y objetos aun personales. Así lo demuestran los libros e inventarios de casas de empeño de la ciudad de México del siglo XIX, en los que figuran prendas como rebozos, frazadas y enaguas. Sin embargo, infinidad de objetos podían ser empeñados en estos establecimientos, así lo demostraba el reglamento sobre casas de empeño de 1871, el cual excluyó de los objetos prohibidos los utensilios de plata, algo que posiblemente generó su incremento en los inventarios de estas instituciones y, en correspondencia, del robo de éstos. Vid. FRANCOIS, Marie Eileen, A culture of everyday credit. Housekeeping, pawnbroking, and governance in Mexico City, 1750-1920, pp. 4, 107-109. 
motivos de dicho código, advirtió sobre una incorporación que mereció un tratamiento especial en el código: el "abuso de confianza", un agravante que anteriormente apenas si se mencionó en leyes y decretos. De acuerdo con Martínez de Castro, más que una circunstancia agravante, el abuso de confianza era "un delito especial" dado que a su entender representaba dos delitos:

"el de apoderarse alguno de una cosa ajena mueble, sin derecho y sin consentimiento de su dueño, que es lo que constituye el robo; y el de disponer indebidamente de una cosa ajena que se recibió en confianza, o a virtud de un contrato que no trasfiere el dominio.” ${ }_{31}$

Conforme los propietarios encontraban poca utilidad en la legislación jalisciense para controlar a su población trabajadora, dado que muchos jueces atenuaban los delitos por razones de pobreza, poco a poco tal ineficacia legal fue tomada por algunos legisladores, a tal grado que fue preciso incorporar agravantes en delitos cometidos en circunstancias domésticas y laborales. Uno de ellos fue precisamente el "abuso de confianza". Tal circunstancia dentro de los delitos de robo se consideró un agravante, y por tal se volvió un arma de doble filo para los acusados, pues si algunos gozaron de toda la confianza por parte de sus patrones, esta condición se volvía completamente en su contra cuando algunas prendas, objetos o semovientes desaparecían. En esos momentos se rompían aquellos vínculos paternalistas entre sirvientes y patrones, o bien, se refrendaban cuando los patrones tal vez sólo buscaban reprender a sus trabajadores. De cualquier manera, ciertas lealtades, protecciones y reciprocidades podían volcar en desconfianzas, injurias y denuncias contra los sirvientes y trabajadores domésticos. En esos casos, pues, se habría rebasado el límite de la confianza. ${ }^{32}$

${ }^{31}$ MARTÍNEZ DE CASTRO, Antonio, Exposición de motivos del Código Penal vigente en el Distrito Federal y territorio de la Baja California. México: Imprenta de Francisco Díaz de Léon, 1876, p. 41.

32 Fabiola Bailón ha detallado bajo algunos estudios de casos, en específico judiciales, la manera en que varias servidoras domésticas de la ciudad de Oaxaca quedaron envueltas en delitos con la circunstancia agravante del "abuso de confianza". Sin embargo, a manera de contrapelo, reconoce que esa clase de causas judiciales no sólo demuestran lo que los amos explícitamente reclamaban de sus sirvientes, sino además, que las acciones que éstos llevaban a cabo fueron una forma de resistencia o respuesta para resarcir un daño recibido en su dignidad y honradez, por malos tratos o pagos incumplidos. BAILÓN, op. cit., p. 343. 
Recientemente se han aplicado en la historiografía mexicana modelos de interpretación que dan cuenta de posibles conductas de algunos sectores sociales, para resistirse ante agravios y rupturas a su economía moral, así como de algunas formas de resistencia que no implicaban necesariamente una confrontación directa, sino que lo hacían a través de acciones o discursos ocultos, difíciles de decodificar para quienes los subordinaban.33 Estas formas de descontento comúnmente se dirigían contra un estado inequitativo de cosas y son reconocidas a través de un conjunto de resistencias cotidianas, traducidas por ejemplo en robos, abigeos o ausentismos laborales. Sin embargo, cuando estas expresiones de resistencia se volvieron recurrentes, llamaron la atención tanto de autoridades como de grupos de poder locales, quienes crearon estrategias para sofocarlas a través de un endurecimiento de los aparatos de control, ya fuera mediante la creación de leyes o declaraciones unilaterales contra toda actividad que se asociaran a ellas.

Al parecer, tal fue el desprestigio y la desconfianza que recayó sobre los sirvientes domésticos, que en febrero de 1885 el Gobierno del Distrito Federal expidió un Reglamento de Criados debido a los "frecuentes casos de robo cometidos por domésticos", por el cual se diseñó un "libreta” en la que se debía incluir todo el historial y perfil de los criados. 34 Llama la atención que en su artículo $12^{\circ}$ se dictaron instrucciones para los patrones, a quienes se les recomendó, en caso de sufrir un robo, acudir a las inspecciones de policía. 35

Poco tiempo después, en 1888, la Jefatura Política de Guadalajara decretó su propio Reglamento de Criados. En él quedó proyectada una exigencia de las principales familias tapatías, que veían en esa clase de servidores una

33 FALCÓN, Romana, México descalzo. Estrategias de sobrevivencia frente a la modernidad liberal, México, Plaza y Janés, 2002; SCOTT, James, Weapons of the weak. Everyday forms of peasant resistance, New Heave, Yale University Press, 1985; LOPES, María Aparesida S. de, De costumbre y leyes. Abigeato y derechos de propiedad en Chihuahua durante el porfiriato, México, El Colegio de México, 2005.

34 Este reglamento puede tener sus antecedentes en el que fue emitido en 1852, en donde también se obligaba a los sirvientes presentar un historial de sus servicios. Una medida que respondía a la necesitad que tuvieron las élites por proteger su propiedad privada. FRANCOIS, op. cit., p. 108.

35 "Reglamento de criados domésticos", en DUBLÁN, Manuel; LOZANO, José María. Legislación Mexicana o Colección Completa de las Disposiciones Legislativas expedidas desde la Independencia de la República, t. XVII, México, Imprenta y Litografía de Eduardo Dublán y Comp., 1887, p. 136. 
seria amenaza. Por tanto, igualmente se demandó el registro de cada uno de ellos en libretas que debían presentar ante las autoridades y sus contratantes. Dicho documento, de acuerdo con el Reglamento, incluiría sus antecedentes laborales respaldados con el testimonio de por lo menos dos personas de "buena reputación que abonen su conducta y su honradez”. Así, el sirviente que fuese sorprendido sin su respectiva libreta sufriría la pena de hasta 30 pesos e incluso la reclusión; medida que se podía extender aun para aquellos que los contrataran. ${ }^{36}$ Asimismo, este control fue acompañado por registros fotográficos que, como han demostrado otros estudios, reflejaron algunas composiciones artísticas y de indumentaria, que fotógrafos y familias intentaron moldear en sus trabajadores. ${ }^{37}$

\section{Sirvientes en el conflicto judicial}

El presente apartado está dedicado a detallar algunas circunstancias particulares que ha sido posible registrar gracias al uso de fuentes judiciales, documentos que también pueden invitarnos a revisitar la esfera doméstica desde las relaciones de poder, de género y de clase, y a contrastar esas supuestas realidades con la representación convencional que se tenía y se tiene de las servidoras domésticas, por ejemplo, a través de la literatura y el reglamentarismo.

El año de 1873, en la ciudad de Guadalajara, el médico cirujano Ramón Urzúa acudió a la jefatura para denunciar a Gabina Ulloa, mujer que servía en su casa, manifestando que le había robado varias prendas, como "unos pedazos de mascada y otros de saco de indiana", sin olvidar unos calzones que sobre la pretina tenían marcado su nombre. Gabina era viuda y de 30 años de edad, y a diferencia de muchos sirvientes domésticos, mantenía su domicilio fuera de la casa donde servía. Alegó no ser cierta la versión de su patrón, pues la esposa de

\footnotetext{
36 "Reglamento de Criados", en Colección de Leyes y Decretos, $2^{\mathrm{a}}$ colección, t. XII, pp. 10-12.

37 Gracias a la conservación que se tienen de algunos libros de registros de criados de la ciudad de Guadalajara, se ha dado pie a importantes colaboraciones que utilizan estos procesos de control social como ventanas para conocer la indumentaria popular y la estética de los primeros fotógrafos de la ciudad. Véanse por ejemplo: CAMACHO, Arturo "Arte y simulación: imágenes de las clases populares en Guadalajara durante el porfiriato", en Letras Históricas, núm. 2, 2010, pp. 157-185; BASTARRICA, Beatriz "En manos del fotógrafo: la construcción de las representaciones de la mujer y de la fachada personal femenina en la fotografía decimonónica mexicana”, en Relaciones, núm. 140, 2014, pp. 43-69.
} 
éste le había regalado tales prendas por estar muy usadas e "inservibles". ${ }^{38}$ Gabina no pudo demostrar que las prendas le fueron entregadas, por lo cual fue declarada culpable por hurtar las mismas. Sin embargo, a consideración del juez, dado que el valor de las prendas era de "poca cuantía" y de que Gabina llevaba más de 15 días detenida, se debía dar por compurgada su pena, dado lo cual fue puesta en libertad.

Un caso semejante se presentó en 1880, cuando Lucía García, mujer de 30 años de edad que sirvió durante algunos días en la casa de la joven María Quirina Padilla, fue denunciada por ésta ante las autoridades del octavo cuartel de Guadalajara bajo el argumento de haberle robado una medalla de plata, algunas llaves y una boleta de empeño. Tras ser interrogada, María Quirina declaró nunca haberle tenido confianza. Lucía ratificó el hecho alegando que ante la negativa de aquélla por quererle pagar "un peso de su servicio", determinó cobrarse con dicha prenda.39 Pese a que Quirina perdonó la injuria, Lucía fue condenada a un mes de prisión en la casa de recogidas. 40

Bajo la revisión que se puede hacer de los múltiples casos que se localizan en los archivos judiciales, los sirvientes domésticos no sólo eran presa de contantes acusaciones por parte de sus patrones, sino que éstas respondían a las acciones que algunos de aquéllos efectuaban, quizá, en respuesta a un acto de injusticia o a la falta de todo acuerdo implícito de reciprocidad que se extendía entre patrones y sirvientes. Siguiendo a James Scott, el robo pudiera haber representado tanto un abuso de confianza bajo la perspectiva de los patrones (y por tanto el rompimiento a las "normas de reciprocidad"), como una expresión

\footnotetext{
38 BPEJ, AHSTJ, RC, "Criminal contra Gabina Ulloa por hurto", Guadalajara, 1873, 46507. 39 BPEJ, AHSTJ, RC, “Criminal contra Lucía García por hurto”, Guadalajara, 1880,

40 En 1880 la Casa de Recogidas de Guadalajara ya dejaba de estar incluida dentro del conjunto que conformaba el templo de Nuestra Señora del Pilar, pues se cuenta con testimonios de que desde 1873 la Penitenciaría de Escobedo ya incluía un Departamento de Mujeres, al cual las autoridades seguían denominando casa de recogimiento o de recogidas; de hecho, y aunque se ha afirmado que los fines de beneficencia que caracterizaron a ese primer establecimiento fueron suplantados por los de una simple reclusión, la Penitenciaría continuaba otorgando a rectoras el control de dicho Departamento. RODRÍGUEZ RAYGOZA. op. cit., pp. 45-63; TRUJILLO BRETÓN, Jorge A.. Entre la celda y el muro: Rehabilitación social y prácticas carcelarias en la penitenciaría jalisciense "Antonio Escobedo" (1877-1911), tesis de doctorado en Ciencias Sociales, Zamora, El Colegio de Michoacán, 2007, p. 161.
} 
"oculta” de resistencia, un recurso para remediar el agravio sin llegar a la confrontación. ${ }^{41}$

\section{Boleta de empeño a nombre de María Flores}

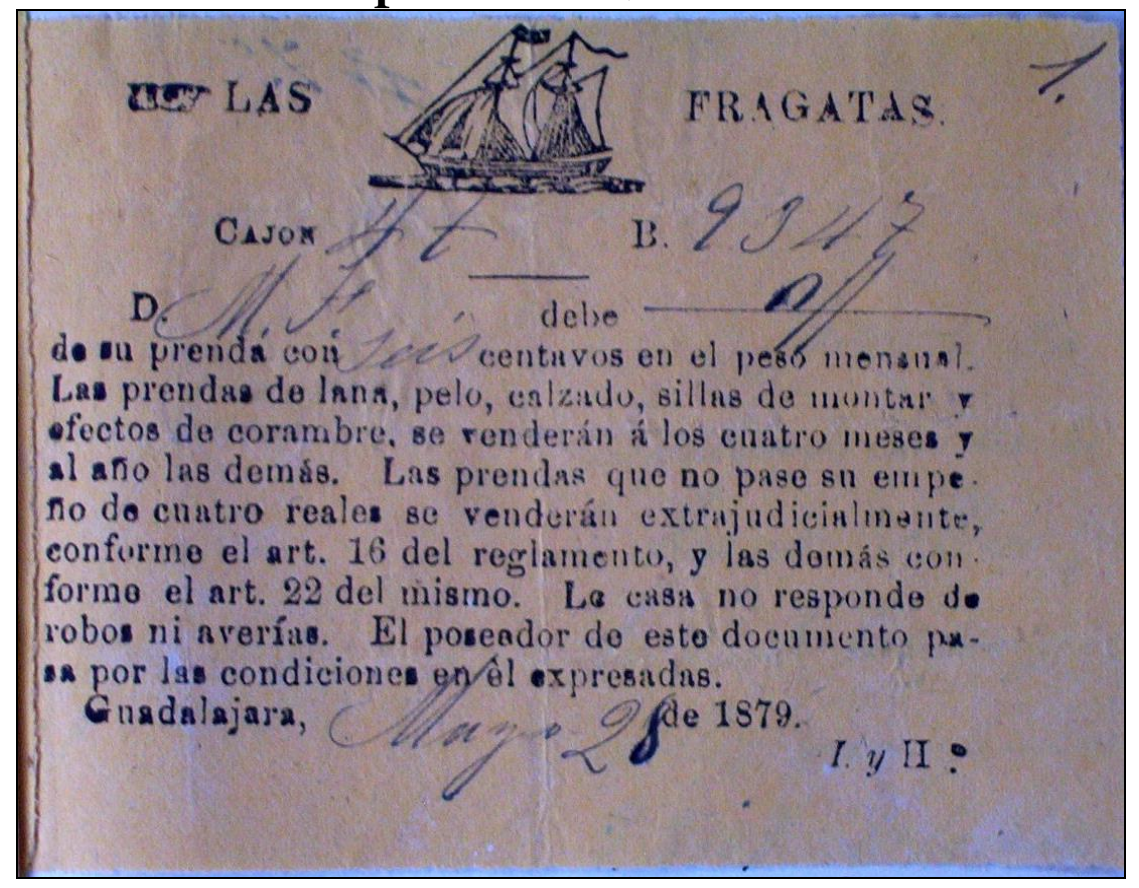

Fuente: BPEJ, AHSTJ, RC, “Criminal por hurto contra María Flores”, Guadalajara, 1879, f. 1.

Otro caso se dio por la garita de Mexicaltzingo, cuando la joven molendera María Flores, quien en 1879 servía en la casa de Petra Ceballos, le tomó “por necesitad que tenía” un rebozo que empeñó en el montepío de "Las Fragatas" con la supuesta intención de devolverlo después. Sin embargo, puede verse que la causa formada contra María Flores se inició precisamente porque su patrona, tras haber regresado de vender sus tortillas, le encargó cuidara la casa y al no ver el rebozo a su regreso, sospechó que ella lo había tomado. Petra agregó que "no le tenía ninguna confianza”, ya que apenas tenía quince días de trabajar con ella..$^{2}$ Asimismo comprobó la propiedad del rebozo, pues algunas de sus vecinas declararon ver a María Flores taparse con él; por tanto, acudió a denunciarla a la Inspección. Al final, la acusada fue sentenciada a un mes de prisión en la casa de recogidas.

${ }^{41}$ SCOTT, James, Los dominados y el arte de la resistencia. Discursos ocultos, trad. de Jorge Aguilar Mora, México, Era, 2000; SCOTT, James, The moral economy of the peasant. Rebellion and subsistence in Southeast Asia, New Haven, Yale University Press, 1976.

42 BPEJ, AHSTJ, RC. “Criminal por hurto contra María Flores”, Guadalajara, 1879. 
Esta clase de incidentes fueron muy comunes y muchos de ellos terminaron dirimiéndose en los juzgados. Así como existieron muchas sirvientas que permanecieron bajo el techo de familias acomodadas, ganándose el sustento y la confianza de todos sus patrones; hubieron otras que no lo consiguieron, algunas veces por desavenencias con ellos, por consejo y complicidad de sus amantes o, como solía suceder, por el simple abuso de confianza.

\section{Retrato de media filiación de María Flores}

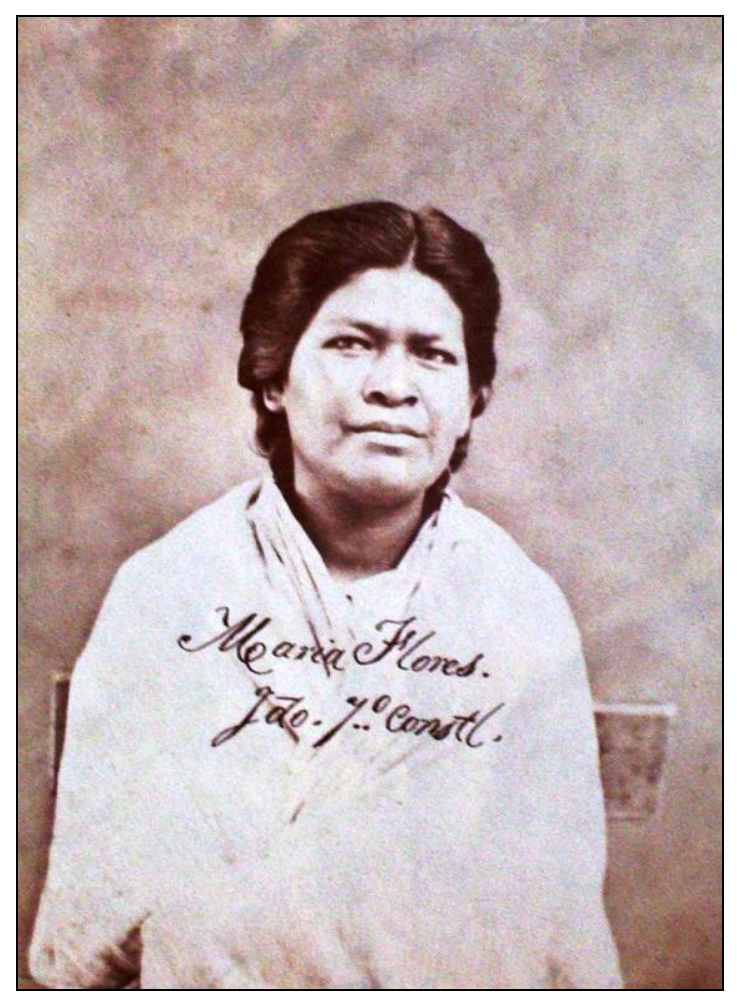

Fuente: BPEJ, AHSTJ, RC, “Criminal por hurto contra María Flores”, Guadalajara, 1879, f. 5.

Por tanto, cuando se cometían robos de carácter doméstico, no fue raro que las primeras sospechas recayeran sobre los sirvientes. ${ }^{43}$ De hecho, María Flores fue acusada en un primer momento por hurto y abuso de confianza, pues para las autoridades parecía un delito asociado que cometían comúnmente los sirvientes; pero su patrona, Petra Ceballos, negó tenerle confianza alguna, algo que aminoró, a favor de María, el grado de la sentencia.

43 TEILTELBAUM, Vanesa E., "Sectores populares y 'delitos leves' en la ciudad de México a mediados del siglo XIX”, Historia Mexicana 220, v. LV, n. 4, México, El Colegio de México, abril-junio 2006, pp. 1250-1251. 
A inicios del siglo $\mathrm{XX}$, para los médicos e higienistas, los sirvientes representaban una amenaza para la salud de las familias decentes. Miguel Galindo, médico que realizó sus estudios en la ciudad de Guadalajara a comienzos del siglo XX, declaró que las enfermedades - como la tan propagada tuberculosis - tenían muchos maneras de contagio y, una de ellas, era el contacto con las clases más pobres. Pensamiento que compartía el común de los médicos, pues se creía que al no poseer los elementales hábitos de higiene -y de acceso a la salud, pensaríamos ahora-, eran presa fácil de las enfermedades. Éstas, refirió el doctor Galindo, tenían origen en la pobreza:

“...el contagio sigue este camino: el amante de la sirvienta lo lleva a ésta; ésta lo pasa a su amo o al hijo del amo; el hijo de ese amo lo pasa a la novia mediante el beso [...] ahora hay que llevar la desconfianza en todo.44

Bajo esta cadena de contagio Galindo compartió un prejuicio que lo llevó, implícitamente, a advertir a las principales familias de Guadalajara sobre los cuidados que debían de tener al momento contratar e interactuar con su servidumbre, ya que, por ejemplo, las nodrizas, si estaban infectadas, podían proporcionar sus besos y "caricias enfermas" a los niños indefensos.

Ahora bien, si para los hombres el aprendizaje fue reconocido como uno de los pocos mecanismos con los que podían hacerse de un oficio, en el caso de las mujeres este mismo proceso pudo haberse homologado con el servicio doméstico, actividad de la que no quedaron excluidos los hombres. De igual manera, la accesibilidad al trabajo doméstico por parte de las mujeres pudo haber respondido a las pocas posibilidades que tenían para obtener otros empleos; además, como criadas o sirvientas no sólo garantizaban un ingreso, sino además vivienda y comida y, en el mejor de los casos, la incursión dentro de nuevos estilos de vida en aras de un aparente ascenso social. 45

Por igual y como sucedió con los hombres de los estratos inferiores que fueron objeto de una variedad de políticas reformistas, las mujeres estuvieron sujetas a una vigilancia que les exigió ocuparse en labores apropiadas -pero

44 GALINDO, Miguel, Higiene social y medicina legal, Tesis de recepción, v. 2, Guadalajara, 1908, p. 35 .

45 SARASÚA. op. cit., pp. 197-257. 
ante todo honradas- para su sexo. Así, mientras los hombres desocupados fueron forzados a ejercer ciertos oficios, las mujeres debían dedicarse a las labores domésticas que incluso les dieran la capacidad de incursionar en la vida fabril, ya fuera como costureras, cigarreras, obrajeras o botoneras, entre otras tareas. Y aunque poco obtuvieran por tales afanes, refirió el influyente José López Portillo y Rojas, otorgaban a la mujer vida honrada: "la aparta de la holganza, que es tan perniciosa, y la libra de las tentaciones, [...] lo que importa es que seáis laboriosas, buenas y amantes del hogar". ${ }^{46}$ Es importante incluir estos comentarios porque en buena medida explican la casi inexistencia de mujeres vagas dentro de las causas judiciales, a pesar de que muchas compartieran las condiciones de vida de hombres situados entre el marco legal de la vagancia y las circunstancias habituales del subempleo. 47

El historiador chileno Gabriel Salazar no desestimó la analogía que existía entre la vagancia de los hombres con la vida errante de muchas mujeres, que por no tener oficios estables, eran perseguidas y depositadas de manera forzada en casas "honradas" para servir como criadas. Ante lo cual, toda la élite chilena, dispersa entre hombres de Derecho, de ciencias, de letras y de fe, erigieron leyes contra las mujeres del pueblo que las forzaban al servicio doméstico, acto que las violentaba y discriminaba. Y de la misma manera como se ha descrito para el contexto aquí trabajado, las mujeres chilenas de los sectores populares de mediados del siglo XIX eran, bajo su supuesta ociosidad, potencialmente sirvientas y prostitutas. 48

Puede apreciarse que para los científicos y reformistas sociales de finales del siglo XIX y comienzos del XX, era más preferible, o menos dañina, la criminalidad femenina -en cierto sentido las ladronas- que la prostitución. Razones había varias, pues entre las ladronas existía una menor presencia de taras hereditarias y estigmas degenerativos, como mandíbulas prominentes. Se pensaba entonces que las ladronas, a diferencia de las prostitutas, tenían "más

46 LÓPEZ PORTILLO Y ROJAS, José, Los Precursores, t. III, Guadalajara, Ayuntamiento de Guadalajara, 1976 (1909), p. 154.

47 PÉREZ TOLEDO, “Trabajadores urbanos...” op. cit., p. 188.

48 SALAZAR VERGARA, Gabriel, Labradores, peones y proletarios. Formación y crisis de la sociedad popular chilena del siglo XIX, Santiago de Chile, Ediciones Sur, 1989, pp. 286-299. 
amor propio, su espíritu es más vivo, más enérgico y resistente en la lucha por la vida, son menos perezosas y no temen tanto al trabajo". 49

Tanto para el médico Miguel Galindo como para muchos otros higienistas y moralistas contemporáneos suyos, la imagen pública de las sirvientas y demás mujeres trabajadoras estaba asociada la mayoría de las veces a la prostitución. Así como en el hombre había labores deshonestas y parasitarias, lo mismo sucedía con las mujeres al emparentarlas con la prostitución. Una manera de enmendar la desviación de la mujer cuando arribaba al cauce de la prostitución, era depositarla en lugares donde se le inculcara el trabajo honesto y productivo, en especial, cuando se tratara de las prostitutas "habituales y predestinadas". Siguiendo a Galindo, la holgazanería en las mujeres era la principal causa para que muchas de ellas se inclinaran hacia tal actividad. Las posibilidades de lograr la "redención social de las rameras" debía quedar en manos del Estado a través de sus autoridades sanitarias, pues cuando llegara el momento en que alguna de ellas enfermara y acudiera al Hospital, debían creárseles talleres para fomentarles el amor al trabajo honesto. 50

\section{Conclusiones}

Así como la historia social nos ha demostrado que es posible dirigir la mirada sobre los "otros" actores sociales que permanecían ocultos, tanto por la historiografía tradicional como por ciertos intereses académicos y hasta por las mismas fuentes documentales, por igual nos ha demostrado que esa mirada también se puede extender hacia otras condiciones de la vida social que no sólo involucraba a los hombres marginados. Así, se ha podido incursionar dentro del medio social en que se desenvolvían las mujeres de los sectores populares, que por lo regular se mantenían fuera del estereotipo demarcado por las élites y la opinión pública, puesto que para aquéllas el trabajo representaba una faena doble muy pocas veces reconocida.

A lo largo de este breve ensayo se ha hecho énfasis en el paralelismo que existió, visto desde las políticas de control social, entre el delito y el servicio

49 QUIRÓS, Bernaldo de; LLANAS AGUILANIEDO, J. Ma.. La mala vida en Madrid. Estudio psico-sociológico, Madrid, B. Rodríguez Serra, Editor, 1901. pp. 49-50.

${ }^{\circ}$ GALINDO, op. cit., pp. 358-359. 
doméstico. Para los reformistas mexicanos del siglo XIX la ociosidad en las mujeres de los sectores populares era inadmisible, ya que podía desembocar en la prostitución y con ello atraer otros males sociales, como las enfermedades venéreas y el debilitamiento fisiológico y moral de la raza. La mujer por definición era depositaria de los futuros ciudadanos, condición que la mantuvo sujeta a un cuerpo de leyes que procuraban su corrección. Sin embargo, muchas mujeres, al igual que los hombres, no pudieron ajustarse a las exigencias que dimanaban del orden social que instauró -o prolongó- el Estado liberal mexicano en su proceso formativo. Éste, a grandes rasgos, se circunscribió al "modo honesto de vivir", y muchos oficios y actividades parecían que estaban lejos de representarlo. Ése fue el caso de los sirvientes domésticos que, al igual que la prostitución y otras prácticas populares criminalizadas, debía permanecer reglamentado.

El uso de fuentes judiciales provenientes del ramo criminal permite identificar nuevos temas para entender la vida de los sectores populares y, particularmente en este caso, para retomar el tema del servicio doméstico al momento que las élites administraron su poder e influencia para perseguir y controlar ciertos grupos sociales, ahora bajo una actitud más sistematizada a través del reglamentarismo y la codificación. Tampoco se trata de reproducir en las fuentes judiciales el espacio legal en que fueron controlados los servidores domésticos, sino de cuestionarlo a través de los discursos que los documentos guardan. Se trata de rescatar las voces y el sentir de los servidores domésticos no tanto para verlos como receptores pasivos del prejuicio y de la ley, sino como actores que negociaban y se resistían a ciertos tratos excesivos y poco benevolentes. Lamentablemente el número de casos que aquí se presentó fue reducido y, para que éstos logren mayor representatividad de lo que nos dicen, hará falta ampliar el estudio en el mismo archivo, que hasta el momento ha sido incapaz de proporcionarnos una estadística siquiera formal y sesgada en términos institucionales.

Dentro de las criadas o domésticas se edificó un imaginario pocas veces preferible de las mujeres pobres, ya que representaban, aunque en grado mínimo, formas de degradación. En el fondo fue una nueva manera de etiquetar lo indeseable bajo argumentos "científicos" y de desviar-o tal vez no querer 
reconocer- las causas de ciertos "males" sociales. De ahí se partió a la aprobación de leyes y reglamentos que delimitaron el desplazamiento de muchas mujeres que debían moverse entre el decoro y la virtud, y quedar fuera del vicio y la inactividad.

\section{Fuentes documentales}

BPEJ, AHSTJ, RC Biblioteca Pública del Estado de Jalisco "Juan José Arreola”, Archivo Histórico del Supremo Tribunal de Justicia del Estado de Jalisco. Ramo Criminal.

Colección de los Decretos, $1^{\text {a }}$ colección, tomo XIV, Tip. de Gob. a cargo de J. Guadalupe Montenegro, 1884.

\section{Bibliografía}

ALLEMANDI, Cecilia L. Sirvientes, criados y nodrizas. Una historia del servicio doméstico en la ciudad de Buenos Aires (fines del siglo XIX y principios del $X X$ ), Buenos Aires, Universidad de San Andrés / Teseo, 2017.

ARROM, Silvia M. Las mujeres de la ciudad de México, 1790-1857, trad. de Stella Mastrangelo, México, Siglo XXI, 1988.

ARROM, Silvia M. "Vagos y mendigos en la legislación mexicana, 1745-1845", en BERNAL (coord.), Memoria del IV Congreso de Historia del Derecho Mexicano, t. I, México, UNAM-Instituto de Investigaciones Jurídicas, 1988, pp. 71-88.

ARROM, Silvia M. "Documentos para el estudio del Tribunal de Vagos, 18281848. Respuesta a una problemática sin solución”, en BERNAL (dir.), Anuario Mexicano de Historia del Derecho, México, UNAM-Instituto de Investigaciones Jurídicas, 1989, pp. 215-235.

AGUIRRE, Carlos. "Mujeres delincuentes, prácticas penales y servidumbre doméstica en Lima (1862-1930)", en O'PHELAN, MUÑOZ, JOFFRÉ Y SÁNCHEZ (coords.), Familia y vida cotidiana en América Latina..., pp. 203-226.

BAILÓN, Fabiola, "Trabajadoras domésticas y sexuales en la ciudad de Oaxaca durante el Porfiriato: sobrevivencia, control y vida cotidiana", Tesis de doctorado en Historia, El Colegio de México, 2012.

BASTARRICA, Beatriz, "En manos del fotógrafo: la construcción de las representaciones de la mujer y de la fachada personal femenina en la 
fotografía decimonónica mexicana”, en Relaciones, núm. 140, 2014, pp. 43-69.

BLISS, Katherine Elaine, Compromised positions. Prostitution, public health, and gender politics in revolutionary Mexico City, University Park, The Pennsylvania State University Press, 2001.

BORUCKI, Alex, From shipmates to soldiers. Emerging Black identities in the Río de la Plata, Albuquerque, University of New Mexico Press, 2015.

CAMACHO, Arturo, "Arte y simulación: imágenes de las clases populares en Guadalajara durante el porfiriato", en Letras Históricas, núm. 2, 2010, pp. 157-185.

FALCÓN, Romana, México descalzo. Estrategias de sobrevivencia frente a la modernidad liberal, México, Plaza y Janés, 2002.

FRANCOIS, Marie Eileen, A culture of every day credit. Housekeeping, pawnbroking, and governance in Mexico City, 1750-1920, London, University of Nebraska Press, 2006.

GALINDO, Miguel. Higiene social y medicina legal, Tesis de recepción, volumen $2^{\circ}$, Guadalajara, 1908.

GENOVESE, Eugene, Roll Jordan roll: The world the slaves made, New York, Pantheon, 1974

GUERRERO, Julio. La génesis del crimen en México. Estudio de psiquiatría social, México, Consejo Nacional para la Cultura y las Artes, 1996 (1901).

ISAIS CONTRERAS, Miguel Ángel, Vagos y perniciosos en Jalisco (1867-1887). Una aproximación al estudio de la marginación y reintegración forzada, México, Tesis de Maestría en Historia, Facultad de Filosofía y letras-UNAM, 2005.

LARA Y PARDO, Luis. La prostitución en México, México, Librería de la Vda. De Bouret, 1908.

LIPSETT-RIVERA, Sonya, Gender and the negotiation of daily life in Mexico, 1750-1856, Lincoln and London, University of Nebraska Press, 2012.

LÓPEZ PORTILLO Y ROJAS, José. Los Precursores, tomo III, Guadalajara, Ayuntamiento de Guadalajara, 1976 (1909).

Los mexicanos pintados por si mismos. México, Editora Nacional, 1959.

MCKINLEY, Michelle A., Fractional freedoms. Slavery, intimacy, and legal mobilization in colonial Lima, 1600-1700, New York, Cambridge University Press, 2016. 
NARI, Marcela M. A. "Conflicto social, maternidad y degeneración de la raza", en Lea Fletcher (comp.), Mujeres y cultura en la Argentina del siglo XIX, Buenos Aires, Feminaria Editora, 1994, pp. 207-216.

NASH, Mary (ed.). Presencia y protagonismo. Aspectos de la historia de las mujeres, Trad. de Roser Bredagé, Barcelona, Ediciones del Serbal, 1984.

NÚÑEZ BECERRA, Fernanda. Las prostitución y su represión en la ciudad de México (siglo XIX). Prácticas y representaciones. México, Gedisa, 2002.

O’PHELAN GODOY, Scarlett; MUÑOZ, Fanni; JOFFRÉ, Gabriel R; SÁNCHEZ, Mónica Ricketts (coords.), Familia y vida cotidiana en América Latina. Siglos XVIII-XIX, Lima, Pontificia Universidad Católica del Perú / Instituto Francés de Estudios Andinos, 2003.

PÉREZ TOLEDO, Sonia. “Trabajadores urbanos, empleo y control en la Ciudad de México", en Clara LIDA y Sonia PÉREZ TOLEDO (comps.). Trabajo, ocio y coacción. Trabajadores urbanos en México y Guatemala en el siglo XIX, México, Universidad Autónoma Metropolitana-Iztapalapa / Miguel Ángel Porrúa, 2001, pp. 157-198.

PÉREZ TOLEDO, Sonia. Los hijos del trabajo. Los artesanos de la ciudad de México, 1780-1853, México, Universidad Autónoma MetropolitanaIztapalapa/El Colegio de México, 1996.

POL, Lotte van de. La puta y el ciudadano. La prostitución en Amsterdam en los siglos XVII y XVIII, trad. de Cathy Ginard Féron, Madrid, Siglo XXI, 2005 .

PORTER, Susie R. Working women in Mexico City. Public discourses and material conditions, 1879-1931, Tucson, The University of Arizona Press, 2003.

QUIRÓS, Bernaldo de; LLANAS AGUILANIEDO, J. Ma. La mala vida en Madrid. Estudio psico-sociológico, Madrid, B. Rodríguez Serra, Editor, 1901.

RAMOS ESCANDÓN, Carmen, Industrialización, género y trabajo femenino en el sector textil mexicano: el obraje, la fábrica y la compañía industrial, México, CIESAS, 2005.

RODRÍGUEZ RAYGOZA, Elizabeth. "La Casa de Recogidas. Una institución para proteger, corregir y castigar a las mujeres en Guadalajara durante los siglos XVIII-XIX”, en Revista del Seminario de Historia Mexicana, Universidad de Guadalajara-CULagos, Vol. IX, Núm. 2, verano de 2009, pp. 45-63.

ROUMAGNAC, Carlos. Los criminales en México. Ensayo de psicología criminal, México, Tipografía "El Fenix", 1904. 
SAGREDO BAEZA, Rafael, "La prostitución en el Porfiriato: El caso de la Chiquita”, en O'PHELAN, MUÑOZ, JOFFRÉ Y SÁNCHEZ (coords.), Familia y vida cotidiana en América Latina, siglos XVIII-XIX, Lima, Pontificia Universidad Católica del Perú/Instituto Francés de Estudios Andinos, 2003, pp. 379-408.

SAGREDO BAEZA, Rafael. María Villa (a) La Chiquita, no. 4002. Un parásito social del Porfiriato, México, Cal y arena, 1996.

SALAZAR VERGARA, Gabriel. Labradores, peones y proletarios. Formación y crisis de la sociedad popular chilena del siglo XIX, Santiago de Chile, Ediciones Sur, 1989.

SCOTT, James, The moral economy of the peasant. Rebellion and subsistence in Southeast Asia, New Haven, Yale University Press, 1976.

SCOTT, James, Los dominados y el arte de la resistencia. Discursos ocultos, México, Era, 2000.

SCOTT, James, Weapons of the weak. Everyday forms of peasant resistance, New Heave, Yale University Press, 1985.

SPECKMAN, Elisa; BAILÓN Fabiola (coord.), Vicio, prostitución y delito. Mujeres transgresoras en los siglos XIX y XX, México, UNAM-Instituto de Investigaciones Históricas, 2016.

TEILTELBAUM, Vanesa E. “Sectores populares y 'delitos leves' en la ciudad de México a mediados del siglo XIX”, en Historia Mexicana 220, vol. LV, núm. 4, México, El Colegio de México, abril-junio 2006, pp. 1221-1287.

TEILTELBAUM, Vanesa E. "La corrección de la vagancia. Trabajo, honor y solidaridades en la ciudad de México, 1845-1853" en LIDA y PÉREZ TOLEDO (comps.), Trabajo, ocio y coacción. Trabajadores urbanos en México y Guatemala en el siglo XIX, México, Universidad Autónoma Metropolitana-Iztapalapa/Miguel Ángel Porrúa, 2001, pp. 115-156.

TRUJILO BRETÓN, Jorge Alberto. Entre la celda y el muro: Rehabilitación social y prácticas carcelarias en la penitenciaría jalisciense "Antonio Escobedo" (1877-1911), tesis de doctorado en Ciencias Sociales, Zamora, El Colegio de Michoacán, 2007.

VANDERVELDE, Emilio; MASSART, Juan, Los parásitos de la sociedad. Estudio comparativo sobre los parásitos de la sociedad y los de la naturaleza, trad. del francés por J. Comaposada, Barcelona, F. Granada y Ca. Editores, 1906 (1893). 